\title{
AN INVESTIGATION INTO DYNAMIC PUNCTURE RESISTANCE OF THE POLYESTER NEEDLED NONWOVEN GEOTEXTILES USING VIDEO PROCESSING TECHNIQUE
}

\author{
Zahra Dehghan-Banadaki, Hasan Mashroteh*, Mohammad Saleh Ahmadi
}

Textile Engineering Department, Yazd University, 89168-69511 Yazd, Iran

${ }^{*}$ Corresponding author. Email: mashroteh@yazd.ac.ir

\begin{abstract}
:
In this study, the dynamic puncture behavior of nonwoven needle-punched polyester geotextiles has been studied using video processing technique. Twenty-seven needle-punched geotextile samples were produced by changing areal weight, needle penetration depth and punch density as independent variables. Cone drop test was carried out on the samples. In addition to measuring the hole diameter $(H D)$, the video processing technique with a high frame rate camera was employed to calculate the energy absorbed by geotextile fabric up to puncture point (Ep) and the hole expansion energy (Ee). Multiple linear regression method was used to develop the predicting relationships between independent and reply variables. The models showed that an increase in areal weight results in an increase in Ep, whereas it causes a decrease in Ee and HD. Moreover, increasing punch density and needle penetration depth, leads to less Ep, and more Ee and HD. In addition, it was also found that significant relationships exist for $E p-H D$ and $E e-H D$.
\end{abstract}

\section{Keywords:}

Geotextile, needle-punched nonwoven, dynamic puncture resistance, cone drop test, video processing.

\section{Introduction}

Geotextiles are fibrous materials that nowadays have an undeniable influence on the improvement of technical performance of the construction materials in civil engineering projects. Among the various types of geotextiles, needlepunched nonwoven geotextile fabrics have gained a lot of attention due to advantages such as low cost and high versatility in their physical, mechanical and hydraulic properties. In many applications, the puncture resistance of geotextiles is of critical importance. This is due to the fact that, in most cases, geotextiles are subjected to concentrated forces perpendicular to their plane, due to surface irregularities of the available subgrade or falling sharp stones during installation. These forces may lead to failure of the geotextile in static or dynamic puncture mode.

Ghosh studied the static puncture resistance of some types of woven and nonwoven geotextile fabrics under uniform radial pre-strain. The results showed lower failure strains in puncture when the samples are pre-strained. He concluded that biaxial failure strain would be a more appropriate indicator of the failure strain in puncture than the strains measured in uniaxial tests. [1] Wang et al. evaluated the dynamic puncture resistance of polypropylene woven and nonwoven geotextile fabrics using the energy level method. They claimed that the energy level of geotextile, computed as half the product of the maximum tensile strength and the corresponding strain, is a reliable indicator of the puncture resistance of geotextile.[2] Rawal et al. studied the effect of process parameters on physical and mechanical properties of the needle punched nonwoven geotextiles. Based on the results, the static puncture resistance (CBR) was strongly dependent upon fabric area density and its thickness.[3] Bolt and Duszynsta determined the influence of installation damage on the puncture resistance of geotextiles. An analysis of CBR tests results showed that after installation in an embankment, the puncture resistance of geotextiles will decrease.[4] Koerner et al. studied the static puncture resistance of polyester (PET) and polypropylene (PP) needle punched nonwoven geotextiles according to three different ASTM puncture test methods. The result indicated that the puncture resistance of geotextiles has been measurably increased by changing the material from PET to PP at an equivalent mass per unit area.[5] Carvalho et al. studied the influence of basis weight on the mechanical properties of needle-punched nonwoven fabrics, such as tensile strength, static and dynamic puncture behavior. The results showed that there is a significant correlation between the mechanical properties of tested geotextiles and their basis weight.[6] Seif Askari et al. studied the effect of test speed and the geotextile's unit weight on the static puncture behavior of needle-punched nonwoven geotextile fabrics. The results of the CBR test indicated that the fabric weight parameter significantly influence the puncture resistance as well as puncture energy and elongation, whereas the test speed has some impact on puncture energy and no effect on the elongation.[7]

In most previous studies, the static puncture resistance of geotextiles (mainly CBR) was investigated, and less attention was given to dynamic puncture resistance. As far as the geotextiles performance during installation is concerned, the late property is a vital characteristic in their conventional applications such as separation and erosion control. Therefore, this study aims to investigate the influence of areal weight and needling parameters on dynamic puncture (cone drop) behavior 
of the needle-punched nonwoven geotextile fabrics using video processing technique. In addition to the conventional method of measuring the hole diameter, recommended by the relevant standard test methods, this technique, as a novel one, helps to calculate puncture and expansion energies that are consumed for forming and expanding the puncture hole.

\section{Experimental}

\subsection{Preparation of the samples}

To produce needle-punched nonwoven fabrics, $100 \%$ polyester fibers with average linear density of 10.2 deniers and average length of $92 \mathrm{~mm}$ were processed on a conventional needlepunched nonwoven line including a carding machine, a cross lapper and a pair of needle looms, needling from top and bottom respectively. Both looms were equipped with GrozBeckert barbed needles coded as $15^{\star} 18^{*} 32 * 3$ R333 G1002.

A total of 27 samples were prepared by changing the areal weight (AW), needle penetration depth (ND) and punch density (PD) in a three-level full factorial design. Specifications of the samples are given in Table 1. The three reported areal weights are based on the average values of the tested samples in each level with coefficient of variations of $7.4 \%, 6.8 \%$ and $4.3 \%$ for 446,544 and $690 \mathrm{~g} / \mathrm{m} 2$ fabric areal weights respectively.

\subsection{Dynamic Puncture Test}

The dynamic puncture (cone drop) test was conducted as per EN ISO 13433: 2006. This method determines the dynamic puncture resistance of the geotextile by dropping a $1 \mathrm{~kg}$ steel cone from a height of $500 \mathrm{~mm}$ (Fig1). The specimen is held firmly by a circular clamping device of $150 \mathrm{~mm}$ internal diameter, so that the steel cone can drop onto the center point. The diameter of the resultant hole in the sample is measured using a graduated cone. It is reported as an indicator of the puncture resistance - the smaller the diameter the greater is the puncture resistance. Five specimens were tested from each sample and the average values were reported.

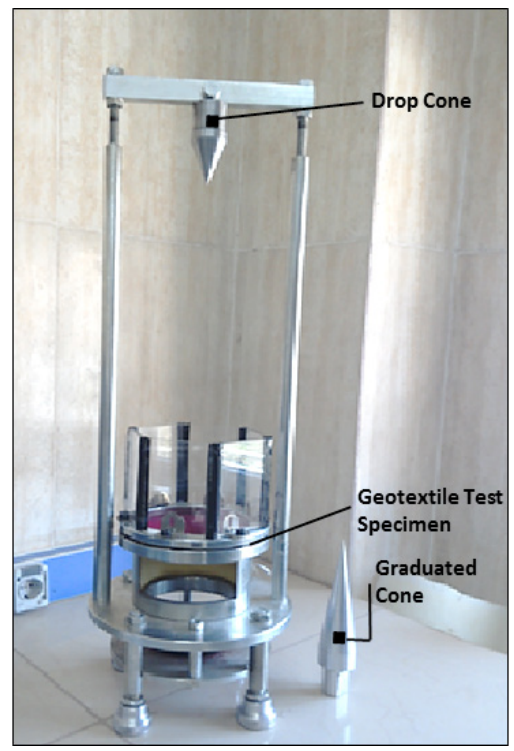

Figure 1. Cone drop test apparatus

\subsection{Video Processing Technique}

The penetration processes of all the cone drop tests were recorded using the high frame rate camera, Sony RX10 II, at 960 frames per second (fps), actual resolution of $1136 \times 384$ pixels and shutter speed of $1 / 8000$ s. Therefore, it is evident that each frame takes long, that is, 1/960 second. The camera was placed perpendicular to the dropping path of the steel

Table 1. Tested samples based on various areal weight and needling parameters

\begin{tabular}{|c|c|c|c|c|c|c|c|}
\hline $\begin{array}{c}\text { Sample } \\
\text { Code }\end{array}$ & AW $\left(g / m^{2}\right)$ & $\mathrm{ND}(\mathrm{mm})$ & $\mathrm{PD}\left(1 / \mathrm{Cm}^{2}\right)$ & $\begin{array}{c}\text { Sample } \\
\text { Code }\end{array}$ & AW $\left(g / m^{2}\right)$ & $\mathrm{ND}(\mathrm{mm})$ & $\mathrm{PD}\left(1 / \mathrm{Cm}^{2}\right)$ \\
\hline$A X a$ & 446 & 10 & 100 & BYy & 544 & 12 & 300 \\
\hline$A X \beta$ & 446 & 10 & 200 & $B Z \alpha$ & 544 & 14 & 100 \\
\hline$A X Y$ & 446 & 10 & 300 & $B Z \beta$ & 544 & 14 & 200 \\
\hline AYa & 446 & 12 & 100 & $B Z Y$ & 544 & 14 & 300 \\
\hline$A Y \beta$ & 446 & 12 & 200 & $\mathrm{CX} \alpha$ & 690 & 10 & 100 \\
\hline AYY & 446 & 12 & 300 & $\operatorname{cx} \beta$ & 690 & 10 & 200 \\
\hline$A Z a$ & 446 & 14 & 100 & CXY & 690 & 10 & 300 \\
\hline$A Z \beta$ & 446 & 14 & 200 & CYa & 690 & 12 & 100 \\
\hline$A Z Y$ & 446 & 14 & 300 & $C Y \beta$ & 690 & 12 & 200 \\
\hline$B X \alpha$ & 544 & 10 & 100 & $C_{Y}$ & 690 & 12 & 300 \\
\hline$B X \beta$ & 544 & 10 & 200 & $C Z a$ & 690 & 14 & 100 \\
\hline BXY & 544 & 10 & 300 & $C Z \beta$ & 690 & 14 & 200 \\
\hline BYa & 544 & 12 & 100 & $\mathrm{CZY}_{\mathrm{Y}}$ & 690 & 14 & 300 \\
\hline$B Y \beta$ & 544 & 12 & 200 & & & & \\
\hline
\end{tabular}


cone, for more accurate results. A 20W LED light was used to supply enough light level that was necessary for recording videos at the possible high frame rate. The set-up of video imaging equipment during cone drop test is shown in Figure 2.

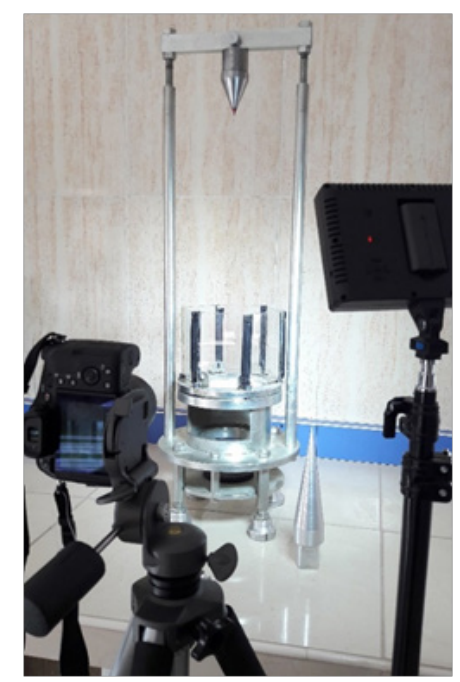

Figure 2. Set-up of the video imaging equipment

The image frames of each video were extracted by the Premier software for all the samples. To determine the momentary speed of the steel cone, it was marked with some stick papers so that they can be traced during successive observations of the frames. It is evident that if the marked point on the steel cone is displaced by the distance of $\Delta \mathrm{X}(\mathrm{m})$ from one frame to the next one, the momentary average speeds $(\bar{V})$ of the cone can be calculated by Equation (1).

$$
\bar{V}=960 * \Delta X(\mathrm{~m} / \mathrm{s})
$$

Figure 3 shows typical variations of the cone speed versus time for one of the samples, between contact times of the cone with fabric to the time it is completely stopped. As can be seen, the data points were meticulously fitted with a quadratic curve using Matlab software. Approximately similar behavior was observed in all data sets of the samples. Therefore, the momentary cone speed at any desired time can be determined using the curve. For example, by checking the recorded videos, if the puncture moment of the cone (the time that the cone starts making a hole in the fabric, as illustrated in Figure 4) is determined to be $21.87 \mathrm{~ms}$, after finding the contact time for the sample in Figure 3, then the momentary speed of the cone at the puncture moment $\left(V_{p}\right)$ can be determined as $2.56 \mathrm{~m} / \mathrm{s}$ using the fitted curve.

Figure 5 displays three steps of a cone drop test. In Figure 5 (a) the cone is in the top position ( $\mathrm{A}$ ) before dropping. As soon as the cone is released, it drops on the fabric and deforms

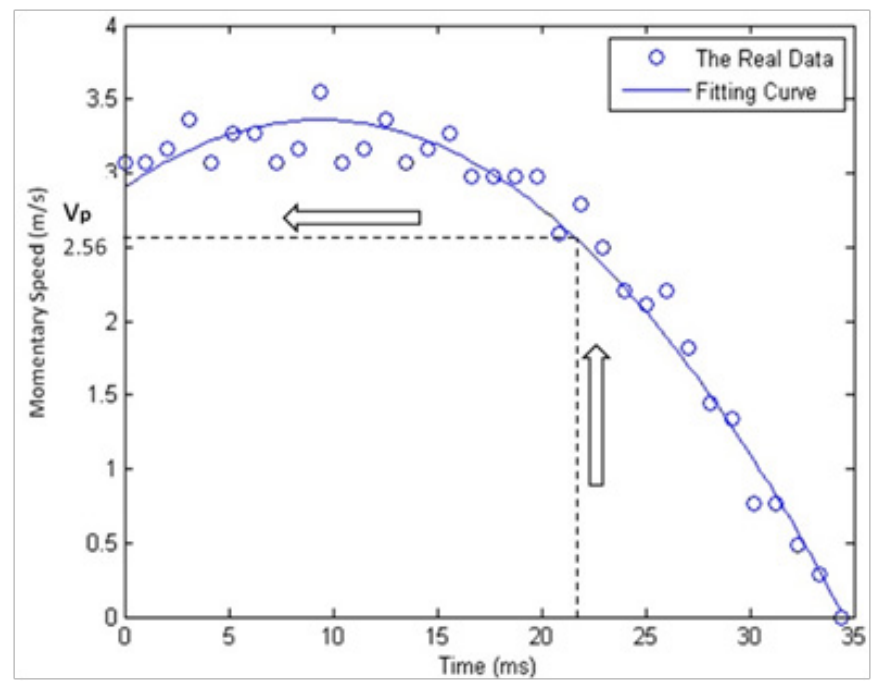

Figure 3. Sample AXß: Optimal curve of the cone momentary speeds

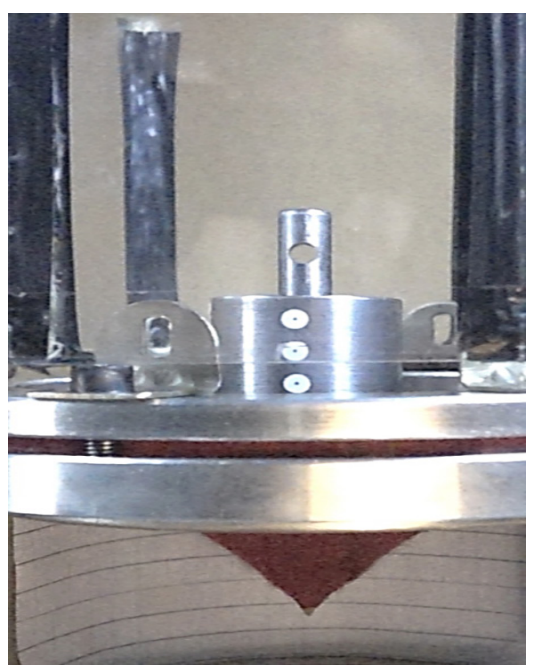

Figure 4. Sample AXß: The frame captured just at the puncture moment
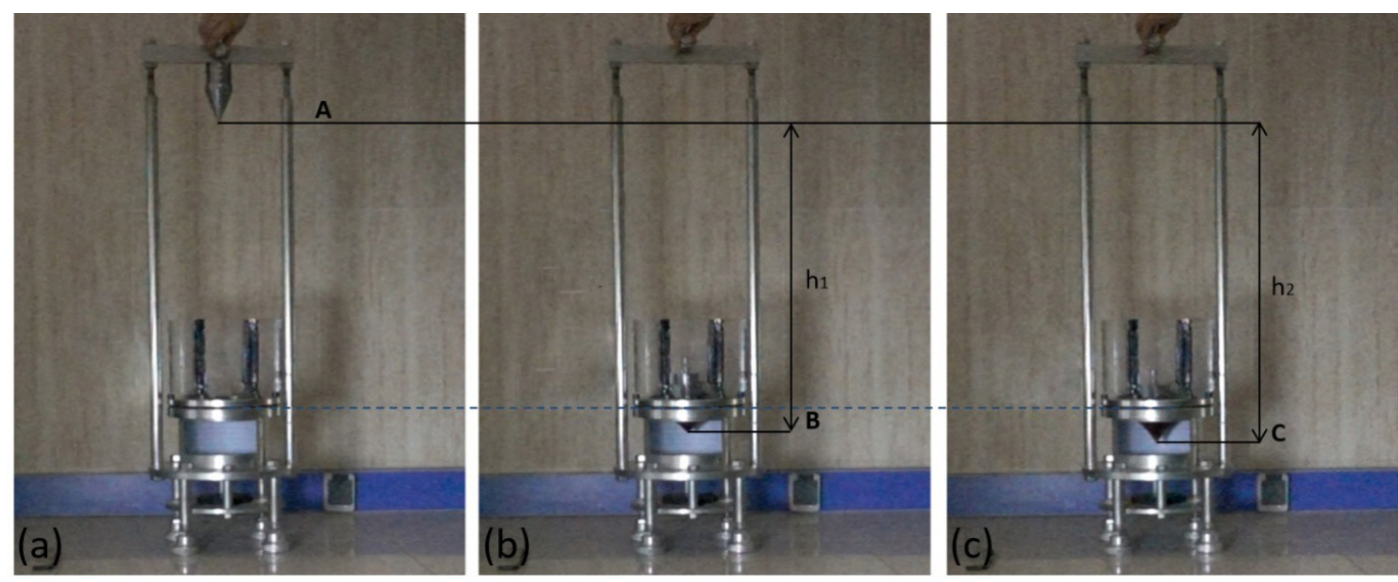

a) before dropping, b) at the puncture point, c) stopping situation

Figure 5. Different situations of the cone 
it until it starts to puncture the fabric (point B in Figure 5(b)). This moment, called as puncture moment, is detected by the high-speed camera as soon as the tip of cone appears from the bottom side of the fabric. At this moment, the cone has travelled the distance of $h_{1}$ from its releasing point $(A)$. The cone continues moving downward with a decreasing speed and expands the created hole on the fabric until it completely stops at point C (Figure 5(c)) after travelling the distance of $h_{2}$ from point $A$. It is called the stoppage moment.

Assume that the camera detects the momentary speed of cone at the puncture moment as $V_{p}$. Therefore, the kinetic energy of the cone is calculated as Equation (2).

$$
\mathrm{K}_{\mathrm{BF}}=0.5^{*} \mathrm{~m}\left(\mathrm{~V}_{\mathrm{p}}\right)^{2}
$$

Where $\mathrm{K}_{\mathrm{BF}}$ is the kinetic energy of the cone at the puncturing moment of the fabric, calculated based on the detected speed by the camera and $\mathrm{m}$ is the mass of the cone.

If it is assumed that there is no fabric and therefore, the cone moves freely all the way, then, based on the law of conservation of energy, the theoretical kinetic energy of the cone at point $\mathrm{B}$, without touching any obstacle $\left(\mathrm{K}_{\mathrm{BW}}\right)$, is equal to the relative potential energy that is stored in the cone due to distance of position A relative to zero position $B$ equal to $h_{1}$ (as calculated by Equation (3)).

$$
\mathrm{K}_{\mathrm{BW}}=\mathrm{U}_{\mathrm{A}}=\mathrm{mgh}_{1}
$$

Table 2. Results of the cone drop test
The difference between $\mathrm{K}_{\mathrm{BW}}$ and $\mathrm{K}_{\mathrm{BF}}$ is the energy spent in puncturing the fabric (puncture energy), as given in Equation (4).

$$
E_{p}=K_{B W}-K_{B F}=m g h_{1}-0.5^{*} m\left(V_{p}\right)^{2}
$$

Similarly, the total energy absorbed by the fabric until its stoppage moment $\left(E_{t}\right)$ at point $C$ can be calculated as Equation (5), due to the fact that at this moment, the momentary speed of the cone is zero. Thus, $E_{t}$ is equal to the potential energy that is stored in the cone due to the distance of position A relative to zero position $C$ equal to $h_{2}$.

$$
E_{t}=m g h_{2}
$$

The difference between $E_{t}$ and $E_{p}$ is the energy spent for the expansion of the hole $\left(E_{e}\right)$, as given by Equation (6).

$$
E_{e}=m g\left(h_{2}-h_{1}\right)+0.5^{*} m\left(v_{p}\right)^{2}
$$

\section{Results and discussion}

Table 2 shows the average values of hole diameter (HD) and

\begin{tabular}{|c|c|c|c|c|c|c|}
\hline Sample Code & $V p(m / s)$ & $h_{1}(m)$ & $h_{2}(m)$ & $\mathrm{HD}(\mathrm{mm})$ & $E_{p}(j)$ & $E_{e}(j)$ \\
\hline $\mathrm{AX} \alpha$ & 2.45 & 0.57 & 0.58 & 9.3 & 2.54 & 3.17 \\
\hline$A X \beta$ & 2.56 & 0.56 & 0.58 & 9.6 & 2.18 & 3.47 \\
\hline$A X Y$ & 2.72 & 0.56 & 0.58 & 12 & 1.76 & 3.96 \\
\hline AYa & 2.59 & 0.56 & 0.58 & 17.6 & 2.08 & 3.61 \\
\hline$A Y \beta$ & 2.78 & 0.55 & 0.57 & 14 & 1.50 & 4.10 \\
\hline$A Y_{Y}$ & 3 & 0.54 & 0.57 & 18.3 & 0.80 & 4.81 \\
\hline$A Z a$ & 2.74 & 0.55 & 0.57 & 18.3 & 1.61 & 3.99 \\
\hline$A Z \beta$ & 2.87 & 0.54 & 0.57 & 18.3 & 1.19 & 4.40 \\
\hline$A Z Y$ & 2.86 & 0.54 & 0.57 & 20.3 & 1.18 & 4.37 \\
\hline BXa & 1.6 & 0.57 & 0.57 & 5.3 & 4.27 & 1.36 \\
\hline BX $\beta$ & 2.5 & 0.56 & 0.58 & 9.3 & 2.3 & 3.29 \\
\hline BXY & 2.7 & 0.54 & 0.57 & 12.6 & 1.6 & 3.92 \\
\hline BYa & 2.46 & 0.56 & 0.57 & 11 & 2.3 & 3.22 \\
\hline$B Y \beta$ & 2.86 & 0.54 & 0.57 & 19.3 & 1.17 & 4.36 \\
\hline BYY & 2.73 & 0.54 & 0.56 & 15.6 & 1.57 & 3.97 \\
\hline$B Z a$ & 2.71 & 0.55 & 0.57 & 16 & 1.71 & 3.91 \\
\hline$B Z \beta$ & 2.86 & 0.54 & 0.56 & 17.3 & 1.16 & 4.36 \\
\hline$B Z y$ & 2.74 & 0.53 & 0.56 & 18.3 & 1.45 & 4.03 \\
\hline$c \times a$ & 1.98 & 0.56 & 0.57 & 5 & 3.51 & 2.06 \\
\hline$C X \beta$ & 2.07 & 0.56 & 0.57 & 7 & 3.29 & 2.26 \\
\hline $\mathrm{CXY}$ & 2.24 & 0.55 & 0.57 & 5.3 & 2.89 & 2.66 \\
\hline CYa & 2.25 & 0.55 & 0.57 & 7.3 & 2.87 & 2.69 \\
\hline$C Y \beta$ & 2.69 & 0.54 & 0.56 & 12 & 1.65 & 3.81 \\
\hline$C_{Y}$ & 2.66 & 0.54 & 0.56 & 10 & 1.77 & 3.73 \\
\hline $\mathrm{CZa}$ & 2.56 & 0.55 & 0.56 & 8.6 & 2.07 & 3.46 \\
\hline$C Z \beta$ & 2.69 & 0.54 & 0.56 & 11.3 & 1.63 & 3.81 \\
\hline CZY & 2.82 & 0.53 & 0.55 & 12.6 & 1.21 & 4.20 \\
\hline
\end{tabular}
the calculated energies. In order to investigate the influence of process parameters on the dynamic puncture behavior of nonwoven needle-punched fabrics, a Multiple Linear Regression Analysis (MLRA) was conducted using SAS 
software. This method is used to explain the relationship between one continuous dependent variable and two or more independent variables. The independent variables in this study are fabric areal weight (AW), needle penetration depth (ND) and punch density (PD), and the dependent (reply) variables are $\mathrm{HD}$, absorbed energy up to the puncture point $\left(E_{p}\right)$ and the energy spent for the expansion of hole $\left(E_{e}\right)$.

\subsection{Statistical Analysis}

A serious problem that may dramatically influence the usefulness of a regression model is the multicollinearity or nearlinear dependence among regression variables. Therefore, Variance Inflation Factor (VIF), as an important multicollinearity diagnostic factor, could be used to detect whether the regressors are correlated with each other or not. In general, the variance inflation factor for the $j^{\text {th }}$ regression coefficient can be written as Equation 7.

$$
\mathrm{VIF}_{\mathrm{j}}=1 /\left(1-\mathrm{R}_{\mathrm{j}}^{2}\right)
$$

Where, $R^{2}$ is the coefficient of multiple determinations. The VIF values less than 0.1 or larger than 10 implies serious problems with multicollinearity, whereas VIF = 1 shows that the analyzed regressors are orthogonal.

The results obtained from the statistical test of Analysis of Variance (ANOVA) showed that independent variables have high intensity of significance effect on all reply variables $\left(P_{r}<0.0001\right)$. On the other hand, the results denote that there is no interaction effect between independent variables at their studied levels.
Finally, conducting MLRA showed that there are relationships between reply and independent variables. The values of VIF obtained 1 for all independent variables and relevant partial plots (Figure 6) show that linear relationship between the reply and the regressor variables was correctly selected.

Based on the results of MLRA, the predicting relationships between independent variables and the reply variables $H D, E_{p}$ and $E_{e}$ are shown in Equations (8), (9) and (10) respectively. Statistical analysis displayed that all of the studied independent variables are significantly effective on the reply variables and needle penetration depth has the greatest influence on all the reply variables.

$$
\begin{aligned}
& H D=2.47-0.03 A W+1.82 N D+0.01 P D \\
& E_{p}=4.48+0.003 A W-0.27 N D-0.004 P D \\
& E_{e}=1.53-0.003 A W+0.26 N D+0.004 P D
\end{aligned}
$$

\subsection{Technical Discussion}

The force applied to the geotextile by the dropping cone first causes the fabric to experience an in-plane strain and deformation due to the movement and slippage of fibers over each other, until the tip of the cone penetrates through the fabric. Up to this moment, the consumed energy is called puncture energy $\left(E_{p}\right)$. Then the cone expands the hole with its remaining energy $\left(E_{e}\right)$ up to its stoppage moment. Figure 7 schematically illustrates the moment of fabric puncture (a) and the expansion of the formed hole (b) which ends to the stoppage of the cone.

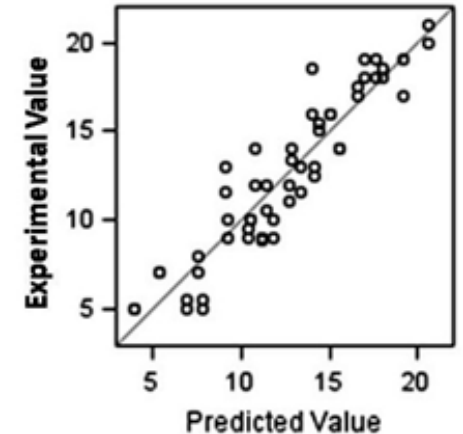

(a)

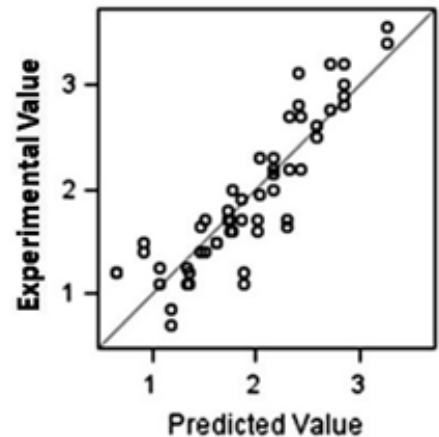

(b)

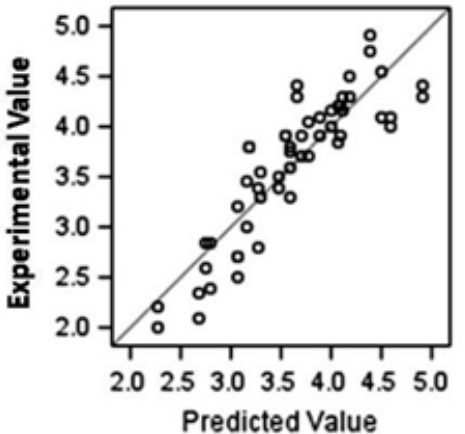

(c)

a) $\mathrm{HD}$,

b) $E_{p}$

Figure 6. Partial plots of experimental versus predicted values for reply variables

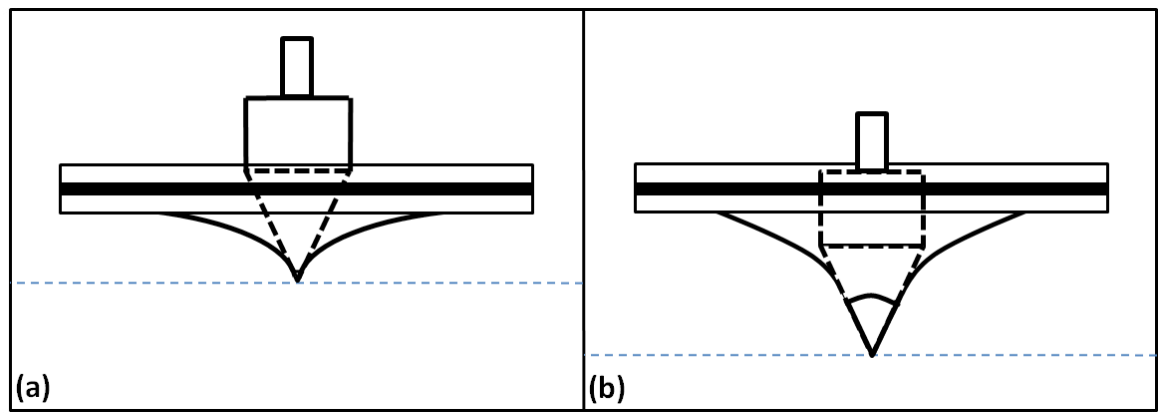

a) Moment of puncture,

b) Expansion of formed hole until cone-drop stoppage

Figure 7. The puncture process 
It is evident that the basis weight of the fabrics can be considered as a vital parameter for many applications. As seen in Equation (9), the more the areal weight, the more the puncture energy. This is due to the fact that increasing the area weight results in more fibers in cross section of the fabric. Thus, it leads to more contact surfaces of the fibers and an increase in the fiber to fiber friction force. Therefore, a fabric with higher areal weight makes the cone lose more speed until the puncture moment and thus, more puncture energy $\left(E_{p}\right)$ is absorbed by the fabric. Consequently, less energy is remained for the cone in order to expand the hole. In other words, the more the areal weight, the less the expansion energy $\left(E_{e}\right)$ (Equations 10). As it is seen in Equation (8), the amount of $\mathrm{HD}$ is also reduced with increasing areal weight of fabric.

An increase in needle penetration depth and punch density clearly causes the fibers to orient more in the through thickness $(Z)$ direction. Therefore, the contact surface of fibers decreases in the in-plane directions. Consequently, when the cone is penetrating the fabric, the fibers slide over each other more easily due to less amount of frictional force between them. Also, it is evident that an increase in the needle penetration depth and punch density can lead to more fiber breakage during needling process. Thus, the penetration of the cone through the fabric can take place more easily. As a result, a fabric with higher ND and PD has less resistance to reduce the speed of cone at the puncture moment $\left(V_{p}\right)$. Therefore, less puncture energy $\left(E_{p}\right)$ is absorbed by the fabric (Equation 9) and larger amount of energy remains for the cone to expand the hole (Equation 10). In this case, the hole diameter (HD) also increases (Equation 8).

As stated earlier, the only parameter reported from the standard test method EN ISO 13433 is the hole diameter produced by the cone. To investigate if there is any relationship between this parameter with each of the calculated energy values $\left(E_{p}\right.$ and $E_{e}$ ), a polynomial of degree 2 (known as quadratic) fitting was performed. Figures 8, 9 show the results of the analysis for $E_{p}$ $\mathrm{HD}$ and $\mathrm{E}_{\mathrm{e}}-\mathrm{HD}$ respectively.

Figure 8 shows that there is a relationship between $E_{p}$ and $H D$ with $R^{2} \approx 0.82$. It is seen that geotextiles with higher $H D$ have lower $E_{p}$. The relationship of $E_{e}-H D$ with $R^{2}=0.84$ is also shown in Figure 9. As it can be seen, fabrics with larger HD absorb more energy for expansion of the hole.

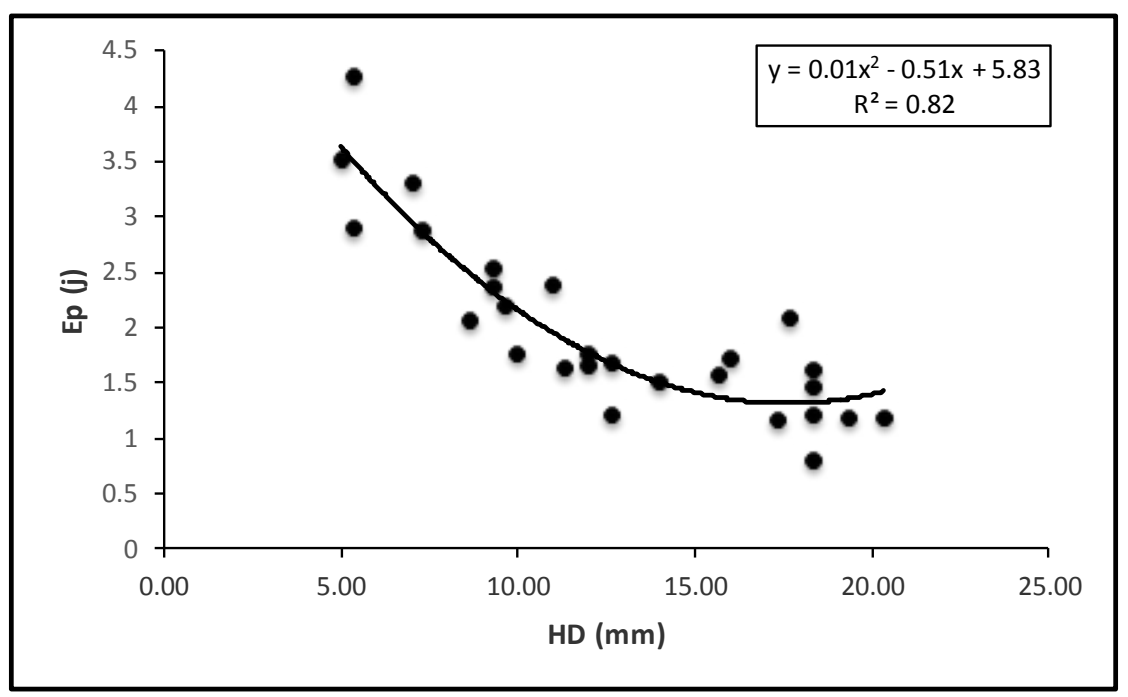

Figure 8. Puncture energy $\left(E_{p}\right)$ versus hole diameter $(H D)$

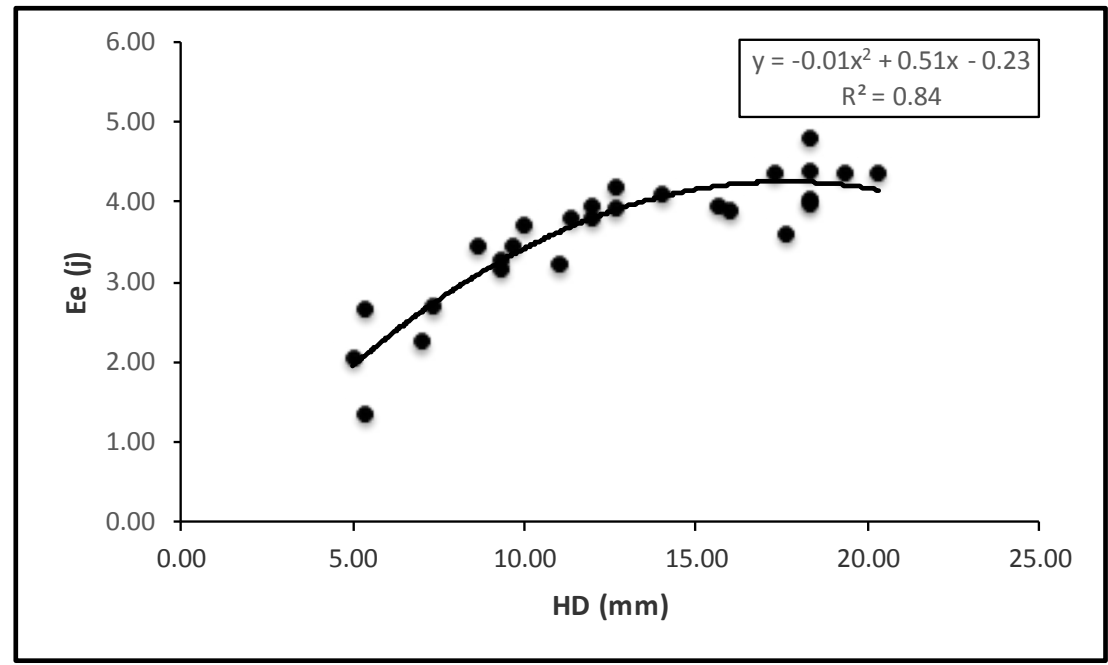

Figure 9. Expansion energy $\left(E_{e}\right)$ versus hole diameter $(H D)$ 


\section{Conclusions}

In order to investigate the dynamic puncture behavior of the nonwoven needle-punched polyester geotextiles, a threelevel full factorial experiment was designed by changing the areal weight, needle penetration depth and punch density as independent variables. The reply variables were the hole diameter (HD), measured by the cone drop test method and the puncture energy $\left(E_{p}\right)$ and hole expansion energy $\left(E_{e}\right)$, calculated by video processing technique. Three separate predicting linear models were developed in order to relate the independent variables to the reply ones by multiple linear regression method. Statistical analysis showed that all the independent variables were orthogonal and they had significant effects on the studied reply variables. The models show that an increase in the areal weight results in an increase in $E_{p}$, whereas it causes a decrease in $E_{e}$ and $\mathrm{HD}$ due to the higher number of fibers resisting against the applied force by the cone. Moreover, increasing the punch density and needle penetration depth leads to less $E_{p}$, and more $E_{e}$ and $H D$. This is due to the fact that it causes the fibers to orient more through the fabric thickness $(Z)$ direction and also, it may lead to more fiber breakage during the needling process. In addition, it was found that significant relationships exist between $E_{p}$ and $H D$, and between $E_{e}$ and HD as well.

\section{References}

[1] Ghosh, T. k. (1998). Puncture resistance of pre-strained geotextiles and its relation to uniaxial tensile strain at failure. Geotextiles and Geomembranes, 16(5), 293-392.

[2] Wong, W. K., Chew, S. H., Karunaratne, G. P. and Tan, S. A. (2000). Evaluating the puncture resistance of geotextiles using the energy level method. In: ISRM International Symposium, Melbourne, Victoria.

[3] Rawal, A., Anand, S., Shah T. (2008). Optimization of parameters for the production of needlepunched nonwoven geotextiles. Journal of Industrial Textiles, 37(4), 341-356.

[4] Bolt, A., Duszyńska, A. (2010). Static puncture resistance of non-woven geotextiles. In: Modern Building Materials, Structures and Techniques, Vilnius, Lithuania, pp.1083-1088.

[5] Koerner, G. R., Koerner, R. M. (2010). Puncture resistance of polyester (PET) and polypropylene (PP) needle-punched nonwoven geotextiles. Geotextiles and Geomembranes, 29, 360-362.

[6] Carvalho, R., Fangueiro, R., Soutinho F. (2011). Mechanical properties of needle-punched nonwovens for geotechnical applications. In: International Conference on Engineering UBI2011, Covilhã, Portugal.

[7] Askari, A. S., Najar, S. S., Vaghasloo, Y. A. (2012). Study the effect of test speed and fabric weight on puncture behavior of polyester needlepunched nonwoven geotextiles. Journal of Engineered Fibers and Fabrics, 7(3), 1-5. 